\title{
Conflict and Harmonization: On Codex Alimentarius Commission' Proposed Guidelines for Genetically Modified Foods Labeling
}

\author{
FU Wenyi \\ Law school, Kunming University of Science and Technology, Kunming, China, 650500 \\ antfuwenyi@hotmail.com
}

\begin{abstract}
The Codex Alimentarius Commission is the most influential international organization for food standards. Since 1993, she began to discuss the issue of genetically modified food labeling, but until now, consensus has not been reached yet. By comparing 7 drafts of the CAC on genetically modified food labeling, it can be seen that consensus on allergic labeling and no-substantial equivalence labeling are formed, but mandatory labeling for ordinary genetically modified food, threshold and exemptions are still on debate. The difficulties for the new standard on this issue are multiple. For genetically modified foods themselves, without final and conclusive scientific conclusion and with big divergence on various interest groups are internal cause; and for the CAC, its close relationship with the WTO is external cause. Negotiations among nations have been lasted for almost 20 years without consensus, from the trend of the standard's discussion, it can draw the conclusion that functions of the CAC are limited and the forthcoming international standard on genetically modified foods labeling will be principled and flexible.
\end{abstract}

Index Terms : The Codex Alimentarius Commission, Genetically Modified Food Labeling

Established by FAO and WHO in 1963, the Codex Alimentarius Commission is the most influential international organization for food standard, who has 185 member states and EU as a member organization. Since 1993, she began to discuss the issue of genetically modified foods (GMF) labeling, but until now, consensus is not formed yet, it swings among different models. There are mainly three ways to label genetically modified foods all over the world, voluntary labeling presented by US, compulsory labeling based on process presented by EU, and compulsory labeling based on product presented by China. Until 2012, the CAC has discussed seven drafts of proposed recommendations for the labeling of food and food ingredients obtained through genetically modification. By comparing the seven drafts, it can be found that little consensus have been reached, but big controversy are still going on. The root causes of failure of $\mathrm{CAC}$ on this issue are worth to think over.

\section{The Consensus has Been Reached}

\section{A. Allergic reactions of GMF}

In 1997, Codex Committee on Food Labeling recommended labeling of potential allergens would apply to the foods obtained through biotechnology [1]. Until 2013, there are 7 drafts on the Genetically Modified Foods (GMF) Labeling issue. Among all the 7 drafts, the 2004 drat is the most detailed and rigid edition, which states that the presence in any food or food ingredients obtained through certain techniques of genetic modification of an allergen transferred from any the products listed in Section 4.2.1.4 of the General Standard of the Labelling of Prepackaged Foods shall be declared [2]. Also the 2010 draft thought that "the presence in any food or food ingredients obtained through biotechnology of an allergen transferred ......should be declared. When it is not possible to provide adequate information on the presence of an allergen through labeling, the food containing the allergen should not be marketed.”[3] Allergic reaction is vital for the health of consumer. Genetically modified technology makes the allergic reaction even more complex for human health. Such as if insert some peanuts gene in genetically modified tomato, the peanut allergic consumer may be allergy to tomato. Lack of allergic labeling indication on the genetically modified tomato will produce potential harm to some consumers who are allergic to peanuts and not knowing the reason to avoid it. The allergic reaction of GMF has been proven by some cases, so labeling to warn allergic reaction of some GMF has gotten the consensus of most states.

\section{B. When the physical, chemical and functional characteristic differ significantly}

Substantial equivalence is the general accepted method to assess and analysis the safety of GMF by international organizations and most countries. 1The 2004 draft states that when food and food ingredients obtained through certain techniques of genetically are no longer equivalent from the corresponding existing food and food ingredients, as regards composition or nutrition value or intended use, a specific approach to the labeling could be used [2]. The 2010 and 2011 draft also require when the physical, chemical, or functional characteristics of a food are significantly altered through any means, the labeling of such food be appropriately modified from its traditional labeling to ensure that the food is described truthful and not misleading manner [4]. When GMF has no traditional counterparts, or its composition and nutrition value are different from common foods, it needs chemical and physical assessment, also labeling is necessary to show the difference.

GMF has entered into market for over 20 years with big controversy. Some GMF have allergic reaction which may bring physiological and mental disorder to human being had

\footnotetext{
${ }^{1}$ Substantial equivalence is established by a demonstration that the characteristics assessed for the genetically modified organism, or the specific good derived therefrom, are equivalent to the same characteristics of conventional comparator (conventional foods or food components already available in the food supply), within the natural variation for such characteristics, based upon appropriate analysis of data.
} 
been appeared in some cases, such as StarLink corn allergic case in US, Brazil nut soybeans carries allergic genes, ect . Being verified by scientific data, allergic reaction of GMF may bright harm to some people' health after eating. Consumers have the right to know this critical information which may directly influence their health. Even those countries in which genetically modified food are labeled by voluntary, allergic reaction should be labeled compulsorily [5]. On the other consensus, when the genetically modified foods are not substantial equivalence to their traditional counterparters, labeling the difference is also compulsory, because the new traits of GMF should be further assessed for safety and the traditional name of such food may need to be changed or qualified with additional words or phrases to describe the true nature of the food and to avoid misleading or confusing the consumer.

\section{Main Controversy}

\section{A. Whether the ordinary GMF should be labeled.}

The 2001 draft and 2004 draft encourage states to label all GMF, thought that food label should be meaningful to the intended consumer. When food and food ingredients obtained through certain techniques of genetic modified, labeling should declare the method of production, and listed 9 examples of declaration [2]. After 2008, those drafts omitted compulsory labeling, just points out that voluntary labeling should not be false, misguide and deceptive. From the discussion process of GMF labeling, it can be seen that at the beginning, states are serious about the safety problem of GMF, and most of them prefer detail and comprehensive standards. With opposition of big planting countries, such as US on this issue, and no obvious side effect on health after many years of eating, the pursuit for standard is weakening. On the GMF compulsory labeling, big divergence appears in the whole discussion process, and can not reached consensus except on allergic reaction and non-substantial equivalence, so CAC have to renounce her efforts for new standard, instead to do more effort on using of existing guidelines.

\section{B. The difference on threshold and exemption}

Threshold level means the minimum level of adventitious or accidental presence of food and food ingredients obtained from genetically modified in the traditional foods in harvesting, processing and transporting. Completely avoided GMF' presence in traditional foods is not possible in practice. From planting to the end products, there are many production or processing procedures, such as seeds buying, crop planting and harvesting, products processing, packaging and selling, threshold is necessary to ensure that very little amount of genetically modified ingredients' occasionally presence in the traditional foods can be ignored, and not need to be labeled. There are different threshold level in the world from $0 \%$ to $5 \%, 0.9 \%$ for Turkey, $1 \%$ for Brazil, $3 \%$ for South Korea and $5 \%$ for Japan [6]. No evidence shows that the difference of threshold will have safety problem, just to ensure the labeling rules more enforceable and show a state's altitude to GMF. In the 2001 draft and 2004 draft, there are threshold ruling, but after 2008, all the drafts deleted this regulations. The reason of this change has some similarity with the first controversy.

Exemption has the similar function as threshold, but it is for highly processed foods, such as milk of cows feed by genetically modified crops. In some circumstances, genetically modified technology is not the main ingredient, just the assistant methods, or can not be detected by today's technology, such as yoghourt made by genetically modified lactobacillus. So under the compulsory labeling system, exemption of some using of genetically modified ingredients is necessary for better enforcement of labeling.

To sum up, the 2001 and 2004 drafts make comprehensive guidelines for compulsory labeling of ordinary GMF. To make it enforced, threshold levels and exemption are the necessary for the accurate labeling so threshold and exemption may play some roles in voluntary labeling also, but under this labeling model, producers are not willing to label their products as genetically modified. Threshold can only be used under rare circumstances, as No-GMF labeling or organic labeling. The Codex Committee on Food Labeling has discussed this issue from 1993. Before 2005, she is trying to regulate guideline of ordinary GMF labeling in a single document, concerning all aspects of labeling. But many years discussion on the compulsory labeling without consensus, after 2008, the guidelines for compulsory ordinary GMF labeling are abolished.

\section{The Difficulties of Forming the Guidelines}

\section{A. The safety of GMF is on dubious in scientific field}

Most standards of CAC are based on science. Lack of scientific support, the standard will not to be trust and maybe abused by states. As for the GMF, allergic reaction or nosubstantial equivalence with traditional food are proved risk, so consensus are reached by states, new standard are forming within the General Standard for the Labeling of Prepackaged Foods and other relating guidelines. The safety of ordinary GMF is still on suspicious under thousand of scientific research, without consensus. States may adopt mandatory labeling according to precautionary principle and the consumers' right to know. Also the states may take no measure just waiting for the long-time scientific evidence. Different models have been adopted by states, compulsory labeling based on process, such as EU, Brazil and Turkey, compulsory labeling based on process, such as Japan, Indonesia, Thailand, Russian and China, and voluntary labeling such as US, Canada, Argentina and South Africa. The mandatory labeling of some states may be regards as non-tariff barriers by other states, so international trade disputes are arouse.

\section{$B$. the serious divergence of beneficial groups}

The benefit conflicts are huge on respect of GMF. On the domestic level, patent owner of seeds, GMF farmers and producers, and industrial groups are in favor of GMF, but traditional crops planters, most consumers and environmental protectors are against it. Different models of labeling policy incline to various beneficial groups, so it is hard to harmonize all their benefit demand. 
On the international level, the US and Canada are the main exporter of GMF, compulsory labeling will bring obstacles to free trade and reduce their export, so they are strongly against it. [7]At the other side, EU and many other third world countries are in favor of compulsory labeling to protect domestic planting farmer and market. It is extremely hard for CAC to harmonize states' benefit.

The compulsory labeling of all GMF is a label for process, without scientific proven. Although CAC has standard for label process without scientific bases, such as organic labeling, hala labeling, the common demand of countries enhance the forming of standards. With the huge divergence of states benefit on GMF, CAC can only form some principle guideline, such as the labeling should not be false, misleading or deceptive, but detailed regulations is not possible.

\section{The CAC close relations with WTO}

In principle, the standards of CAC has no binding for member states, states can adopted them wholly or partially. But with the transfer of GATT to WTO, the binding force and commitments of CAC is strengthened. SPS Agreement clearly said that member states of WTO shall enforce the CAC standards. TBT Agreement said that member states of WTO shall consider the standards established by other international organizations. 2In practice, if a state adopted rules rigid than CAC standards, it needs to be verified by scientific proof; otherwise it may be regards as discriminated and arbitrary. [8]At this point, CAC standards become judgment for whether the domestic rules are conformed to WTO. If CAC adopts compulsory labeling for ordinary GMF without scientific proven, it is not consistent with WTO's goal for free trade, and will be strongly against by US and Canada, may induce trade disputes. Also, the conflict with WTO will have bad influence for CAC, and weaken the effect of its other standards. But CAC can not ignore the issue, since it is the most influential international organization whose responsibility is mainly on food. Lack of GMF labeling guidelines will be a significant defect. So for GMF labeling, CAC is at great dilemma.

\section{Conclusion}

A. The limit of competence of CAC

The main task of CAC is guidance for food safety. GMF concerns not only safety, but also other aspects. Compulsory labeling focuses more on environmental benefit, protection of local biological diversity, consumer's right to know, special diet religion, avoiding the genetic pollution and protecting domestic industries, ect. All these are beyond the safety, extending to human rights, environmental protection, and culture value. Voluntary labeling considers more liberalization of trade, benefit of GMF producers and sellers, free speech of commerce, the patent protection of genetically modified seeds, also the biggest genetically modified planting states. It is impossible for CAC to harmonize the huge conflicts on all

\footnotetext{
2 The Agreement on the Application of Sanitary and Phytosanitary Measures, article 3.1. The Agreement on Technical Barriers to Trade, article 2.6.
}

aspects and find a satisfied solution for all beneficial groups and different value pursuits. .

\section{B. CAC may refer other guidelines, but not adopt special one for $G M F$}

It is good for CAC to keep friendly relationship with WTO, since the enforcement of WTO rules are better. The reference of CAC's guidelines in Disputes Settlement Bodies is beneficial for the widespread of CAC's standards, and its application in member states. But at the other point, this friendship makes CAC to be more cautious and prudent on passing new guidelines. Scientific proof is critical for new standards, without it the guideline may be regards as arbitrary, impeding to free trade, and even be no-tariff barrier, so CAC's competence is limited by the cause of WTO.

In the whole world, most states are both members of CAC and WTO [9], if the new GMF standard of CAC conflict with WTO, it brings the fragment of international law, at the same time, makes member states in dilemma. Now there are over 50 states have adopted rules on GMF labeling, some are voluntary, some are compulsory, others have no rules yet [6].CAC has to respect various existing domestic laws. Neither compulsory labeling nor voluntary labeling can get sustain by most states, so it is not a wise solution for CAC. As an international organization responsible for food safety, GMF is at its scope of work. CAC has to do its effort for guidelines of GMF. Scientific field with the method of risk analysis is easier to get unanimous conclusion; the guidelines will be reached for consensus, such as Principles for Risk Analysis of Foods Derived from Modern Biotechnology (CAC/GL 44-2003), Guidelines for the Conduce of Food Safety Assessments of Goods Derived from Recombinant -DNA plants (CAC/GL 452003). These guidelines are proved by scientific research, unlike labeling without scientific conclusion. On the GMF labeling issue, CAC can only form relax and loosen guideline, such as the labeling shall not be false, shall not lead to confuse and not suggest GMF are necessarily different from other foods simply due to their method production. Recalling and assembling in a single document some important elements of guidance from Codex texts, which are relevant to labeling of GMF is the best way for CAC to guide member states, without chose a labeling approach, just as she has done after 2008.

\section{References}

[1] CAC. Recommendations for the Labelling of Foods obtained through Biotechnology, ALINORM 97/22 A. Geneva, 1997, Appendix. VI. p.65.

[2] CAC, Proposed Draft Guidelines for the Labelling of Foods Obtained through certain Techniques of Genetic Modification/Genetic Engineering: Labelling Provisions. ALINORM 04/27/22, Rome, 2004, Appendix.VI.pp.54-56.

[3] CAC, Proposed Draft Recommendation for the Labelling of Foods and Food Ingredients Obtained through Certain Techniques of Genetic Modification/Genetic Engineering, ALINORM 10/33/22, Geneva, 2010, Appendix.X.,p. 56-57.

[4] CAC , Proposed Draft Compilation of Codex Texts relevant to Labeling of Foods Derived from Modern Biotechnology, REP11_FL, Geneva, 2011, Appendix III.

[5] FDA:Statement of Policy: Foods Derived from New Plant Varieties, 57 FR 22984 at 22,984. (1992). 
[6] Guillaume P. Gruere \& S.R. Rao, A Review of International Labelling Policies of Genetically Modified Food to Evaluate India's Proposed Rule, AgBioForum 2007, Vol.10, pp.53.

[7] International Service for the Acquisition of Agri-Biotech Applications, Global Status of Commercialized Biotech/GM Crops: 2012. http://www.isaaa.org/. Visited on 2013-4-19.
[8] Diahanna L.Post, The Precautionary Principle and Risk Assessment in International Food Safety: How the World Trade Organization Influence Standards, Risk Analysis, 2006, Vol.26, pp.1259-1264.

[9] There are 159 members of WTO until 2 March 2013. http://www.wto.org/english/thewto_e/whatis_e/tif_e/org6_e.htm, Visited on 2013-5-2. 